\title{
O habitus professoral: o objeto dos estudos sobre $o$ ato de ensinar na sala de aula
}

\author{
Marilda da Silva \\ Universidade do Estado de São Paulo, Faculdade de Ciências e Letras, campus de Araraquara.
}

\section{Introdução}

Apresentamos, neste artigo, um modo de pensar a estruturação do objeto das investigações sobre o ensino na sala de aula, que denominamos habitus professoral. A produção dessa idéia iniciou-se no final da década de $1980 \mathrm{com}$ as duas primeiras pesquisas que realizamos, e ganhou estruturas mais estáveis com a produção da dissertação e da tese, defendidas, respectivamente, em 1994 e 1999. ${ }^{1}$ Essa arquitetura contou com as idéias de Pierre Bourdieu (1983a, 1983b, 1983c, 1983d, 1989, 1992, 1996a, 1996b) que culminam na noção de habitus. Outra categoria decisiva

${ }^{1} \mathrm{~A}$ dissertação denomina-se $O$ movimento a didática em questão: alguns de seus embaraços (Silva, 1994). Dela derivou o livro Controvérsias em didática (Silva, 1995). A tese, As experiências vividas na formação e a constituição do habitus professoral: implicações para o estudo da didática (Silva, 1999), foi publicada com o título Como se ensina e como se aprende a ser professor: a evidência do habitus professoral e da natureza prática da didática (Silva, 2003). para o habitus professoral foi a formulada por Edward Palmer Thompson (1981), denominada experiência. As formulações que vêm sendo produzidas nos últimos vinte anos nos Estados Unidos, Canadá e Europa sobre a epistemologia da prática docente foram também imprescindíveis ao intento. Essas produções, como se pode constatar no livro intitulado Saberes docentes e formação profissional, de Maurice Tardif (2002), foram úteis porque visam, principalmente, à definição sobre o lugar da teoria e da prática na formação de professores, tendo em vista as características específicas da natureza de cada um desses saberes, as quais trazem implicações aos modos por meio dos quais esses saberes são apreendidos.

As reflexões sobre as especificidades das propriedades estruturais dos saberes teóricos e práticos que não incluem a dissociação entre eles para o pensar e o agir humano - advindas de autores como Schon, Argyris e Schon, Saint-Arnaud, Calderhead, Bolster, Doyle, Altet e Perrenoud, apresentadas no texto de Tardif, deram substanciais contribuições para o desenvolvimento da nossa pesquisa porque autorizam, em certa medida, o uso que vimos fazendo do concei- 
to de habitus na acepção de Bourdieu e da categoria experiência em Thompson, no esforço de formular uma idéia sobre o ensino na sala de aula. A fertilidade dessa autorização reside, principalmente, no fato de que, ao se apresentar um lugar específico para aprender a teoria e a prática (nesse caso, para a formação de profissionais que atuam na sala de aula), abre-se uma vinculação com o modus operandi da noção de habitus e da categoria "experiência". Esse vínculo, como o leitor poderá observar, possibilita a síntese: o objeto de estudo das investigações sobre o ensino na sala de aula é o habitus professoral. Também não podemos deixar de dizer a virtuosa contribuição advinda dos estudos sobre professores iniciantes. Essas pesquisas contribuíram para fortalecer a base empírica sobre o lugar do aprendizado da teoria e da prática na formação de professores, que estabelece relação direta com a constituição do objeto de estudo em questão.

Ademais, a idéia que será exposta sobre a estruturação do objeto dos estudos sobre o ensino na sala de aula vai ao encontro da resposta à pergunta que Gauthier et al. (1998, p. 87) apresentam quando se referem aos problemas com os quais se deparam quando procuram uma definição sobre a estrutura da prática docente nos estudos que a ela se referem. A pergunta é sobre a natureza dessa prática, tendo em vista uma sistematização que dê conta de mostrar se ela é constituída por uma estrutura estável ou se consiste em um acontecimento singular. Estrutura estável se for uma atividade exercida por meio de uma única estruturação; acontecimento singular se for uma atividade que tem uma estrutura para cada momento de efetivação. Afirmamos: a natureza do ensino na sala de aula é constituída por uma estrutura estável, porém estruturante, isto é, uma estrutura estável mas não estática, que denominamos habitus professoral.

O leitor também verificará facilmente que seria impossível apresentar essa pesquisa sem obedecer à lógica histórico-conceitual de sua produção. Por isso, explicitamos detalhadamente a trajetória dessa formulação. Esse procedimento foi necessário porque não se trata apenas de uma pesquisa, mas de um longo processo de investigação que culminou nesta síntese. Deve-se essa inspiração a Pierre Bourdieu (1989, p. 59) quando observa o entendimento que tem do "partido da ciência”:

Diferente da teoria teórica - discurso profético ou programático que tem em si mesmo o seu próprio fim e que nasce e vive da defrontação com outras teorias -, a teoria científica apresenta-se como um programa de percepção e de ação só revelado no trabalho empírico em que se realiza. Construção provisória que por meio dele ganha menos com a polêmica teórica do que com a defrontação com novos objetos. Por essa razão, tomar verdadeiramente o partido da ciência é optar, asceticamente, por dedicar mais tempo e mais esforços a pôr em ação os conhecimentos teóricos adquiridos investindo-os em pesquisas novas [...].

\section{Os primeiros esteios da idéia}

Os esteios iniciais dessa idéia foram oriundos das primeiras pesquisas que realizamos, as quais dizem respeito ao modo por meio do qual os futuros professores para as séries iniciais do ensino fundamental concebiam a disciplina didática no currículo do curso que os formava, e como esses professorandos acreditavam que se aprendia para ensinar na sala de aula. Esses estudos foram produzidos com dados coletados por meio de instrumentos da pesquisa quantitativa, e deles participaram 700 alunos professorandos de $1^{\mathrm{a}}$ à $4^{\mathrm{a}}$ séries que freqüentavam de 1987 a 1989 a então "habilitação para o magistério". De um estudo fizeram parte 550 estudantes que freqüentavam escolas públicas consideradas de boa qualidade, antigos institutos de educação localizados nas cidades de São Carlos, Araraquara e Ribeirão Preto, no Estado de São Paulo. Do outro, participaram 250 trabalhadores-estudantes ${ }^{2}$ professorandos que freqüentavam uma escola privada

\footnotetext{
${ }^{2}$ Naquele momento, Carvalho (1988) fazia uma reflexão
} sobre o trabalhador-estudante, e sua pesquisa nos foi muito útil, pois possibilitou nossa reflexão sobre o trabalhador-estudante que se preparava para exercer a profissão docente. 
noturna - considerada de má qualidade -, localizada na cidade de Araraquara, do mesmo estado. ${ }^{3}$ Esses dois grupos eram significativamente distintos, no que se refere aos aspectos sociais, econômicos, culturais e acadêmicos, ou seja, os sujeitos que compunham o maior grupo eram originários de setores da classe média e de famílias que dispunham de diferentes e entrelaçados capitais, objetivados e simbólicos, que no Brasil subsidiam o acesso e o sucesso acadêmico dos estudantes: capital material, capital social e capital cultural. Já o outro grupo se distanciava significativamente do primeiro, no que tange a esses recursos.

Os resultados obtidos nessa pesquisa foram muito instigantes, na medida em que os dois grupos de alunos pesquisados emitiram informações que confluíram para uma única resposta: diziam que se aprende a ensinar na sala de aula, ou seja, na prática, mas consideravam a didática como a disciplina que mais ensinava a dar aula, durante a formação. A pergunta evidente que esse resultado impôs foi a seguinte: Por que esses estudantes afirmavam que se aprende a ensinar no exercício da profissão, isto é, na prática, e ao mesmo tempo afirmavam que a disciplina que mais ensinava a ensinar era a didática? Estávamos diante de uma contradição: apesar de afirmarem que se aprende a profissão ao praticá-la, os dois grupos afirmaram também que se aprendia a prática teoricamente, no curso que freqüentavam. Foi dessa contradição que partimos.

A pergunta que formulamos e que cumpriu a função de hipótese foi: será que os 700 alunos, quando diziam que a didática era a disciplina que mais ensinava a ensinar durante a formação e, ao mesmo tempo, diziam que se aprendia a ensinar na prática, não estariam equiparando a natureza do ato de ensinar à natureza do corpus teórico da didática mais utilizado na história brasileira das práticas docentes ${ }^{4}$ até aquele momento, que dizia respeito a um tipo de instru-

\footnotetext{
${ }^{3}$ Essas pesquisas foram publicadas na Revista Didática [ver, respectivamente, Silva \& Marin (1989) e Silva (1993/1994)].

${ }^{4}$ Informações sobre essa história da didática podem ser encontradas em textos de Amélia Domingos de Castro (1984, 1992),
}

mental técnico que era "ativo" somente no momento da aplicação prática? Buscar respostas para essa pergunta implicava desdobrar o resultado do qual ela se originou, já que exigia duas informações distintas, contudo, severamente imbricadas. Tratava-se, portanto, de organizar explicações sobre a didática ensinada para ensinar, e como se aprende para ensinar na sala de aula. Por tal razão, duas sistematizações foram empreendidas: a didática ensinada para ensinar na sala de aula brasileira dos cursos que preparavam professores, e o modo por meio do qual se aprende para ensinar na sala de aula.

\section{A didática ensinada para ensinar na sala de aula brasileira dos cursos que preparavam professores}

Para esse esclarecimento, partimos do pensamento que à época estava sendo produzido no Brasil relativamente à didática - usada, ensinada e pensada - e à formação de profissionais da educação. Desde os anos de 1970 tais inquietações estavam na agenda da produção do campo educacional brasileiro, mas somente nos anos de 1980 o debate ganhou maior visibilidade, com a realização dos três primeiros seminários “A Didática em Questão" (1982, 1983, 1985) e do "IV Encontro Nacional de Didática e Prática de Ensino" (1987), ${ }^{5}$ que materializaram o denominado Movimento “A Didática em Questão”. Os textos derivados direta e indiretamente desses eventos constituíram as fontes da explicação do tema em questão. ${ }^{6}$

Essa pesquisa revelou que os pesquisadores expoentes de tal movimento produziram seus discursos

Denice Bárbara Catani (1985), Ilma Passos Alencastro Veiga (1988), Olga Teixeira Damis (1988), José Carlos Libâneo (1983) e Alda Junqueira Marin (1984).

${ }^{5}$ Apesar de nossos esforços, nada foi possível saber sobre a existência de anais do V Encontro Nacional de Didática e Prática de Ensino, realizado em 1989.

${ }^{6}$ Essa pesquisa culminou em nossa dissertação de mestrado, mencionada na introdução deste artigo. 
com o objetivo de fazer uma crítica severa à didática que se ensinava, à didática que se utilizava para ensinar nos cursos que preparavam professores e professoras e aos modos por meio dos quais se produzia pesquisa nessa área, especialmente no Brasil. Dentre os argumentos mais utilizados nas críticas feitas pelas lideranças do movimento estava a justificação de que o problema maior, que se refletia diretamente na formação dos profissionais da educação, dizia respeito à didática usada para ensinar e a ensinada na e pela disciplina didática. A razão das deficiências da didática usada e ensinada era fruto do fato dessa disciplina ter assumido características da Didática Magna, de Comênio, escrita em 1657, e da pedagogia escolanovista. As lideranças afirmavam que essas propostas pedagógicas não consideravam questões políticas que perfazem o ato de ensinar, reduzindo o ensino a uma atitude eminentemente técnica.

Com essa investigação, foi possível evidenciar que o argumento apresentado pelo movimento foi construído por meio de um equívoco analítico. A principal causa desse equívoco decorreu do fato de que tanto Comênio como Dewey pressupunham, em seus modelos, a construção de um dado homem para viver, produzir e organizar uma determinada sociedade, já que tinham organizado teórico-metodologicamente instrumentos que acreditavam fossem eficazes para se sobrepor à lógica de pensar e agir no mundo material que vigorava no tempo de cada um. A lógica que pretendiam estabelecer, de acordo com suas aspirações, atendia aos seus interesses históricos e políticos, embora justificados por razões distintas. O equívoco foi agravado pela falta de informações empíricas, isto é, pela falta de pesquisas suficientes do cotidiano escolar que permitiriam confrontar os planejamentos de ensino da disciplina didática que hipoteticamente eram desenvolvidos nos cursos que formavam professores para as séries iniciais do ensino fundamental, que serviram de fonte a muitos dos pesquisadores que participaram do movimento. Não obstante, "A Didática em Questão" explicitava a ausência de uma base empírica que pudesse ampliar as informações sobre qual o tipo de didática que era, de fato, usada e ensinada na sala de aula dos cursos de formação pedagógica. Contudo, manteve a afirmação de que essas didáticas fundamentavam-se em Comênio e na Escola Nova.

Para os expoentes do movimento, mais diretamente envolvidos com a didática - dentre eles, André (1988, 1992), André e Mediano (1988), André et al. (1984), Candau (1988a, 1988b, 1988c, 1988d, 1988e, 1988f), Candau e Lellis (1983), Libâneo (1983), Martins (1989), Oliveira (1988), Silva (1983, 1985), Soares (1985) -, a racionalidade da Didática Magna de Comênio e dos escritos de Dewey destinados à educação (dentre eles, o livro Experiência e educação) não permitiam movimento entre os conteúdos que a escola ensinava e o contexto sócio-históricocultural da sociedade, tendo em vista a mudança desse contexto. O que se pôde dizer é que esses pesquisadores não viam, nas duas proposições, instrumentos ou recursos metodológicos eficazes para provocar o estabelecimento de relações entre os conteúdos curriculares e as características da sociedade, tendo em vista a produção de uma sociedade justa e democrática. Todavia, Comênio e Dewey visavam a um tipo de organização social em harmonia com suas proposições didáticas, que visivelmente sustentavam interesses de caráter político, como mostraram de diferentes modos e com objetivos distintos Gasparin (1992) e Cunha (1994). Para o movimento, a saída era, então, reconstruir a didática, já que sua identidade (Soares, 1985) encontrava-se em crise, de certo modo, porque pendulava entre procedimentos comenianos e escolanovistas, entre outros fatores mais gerais oriundos das características do desenvolvimento da educação escolarizada no Brasil.

A didática sugerida para substituir a didática constituída por procedimentos duros e alienados, proposta no século XVII e no século XX, articularia as dimensões técnica, política e social que caracterizam o ato pedagógico crítico. E foi denominada "didática fundamental". Sua formulação justificava-se, sobretudo, pelo fato de a escola brasileira estar saindo da égide de um regime autoritário, demandando o uso de procedimentos didáticos que levassem os alunos à 
desalienação, com vista a oferecer uma escola de boa qualidade para a maioria da população e uma sociedade justa para todos. É inegável que o Movimento “A Didática em Questão” prestou um serviço necessário à escola e à nação na medida em que instituiu, apesar de seus equívocos, um discurso crítico explícito sobre os modos de ensinar nas escolas, bem como contribuiu para que se alargassem os modos de pesquisar na área da didática e no campo educacional brasileiro de modo geral.

No entanto, o movimento - que havia se dedicado inteiramente à didática ensinada, usada e pensada no contexto brasileiro e feito uma espécie de estado da arte - não havia conseguido mostrar qual era, de fato, a didática ensinada e usada na sala de aula dos cursos que preparavam professores no país à época. Se o resultado não havia sido satisfatório ao intento em processo, ele reforçava a necessidade de continuar no caminho que estava sendo trilhado. Investimos, então, na outra etapa que já estava programada: investigar como se aprende para ensinar na sala de aula.

\section{O modo por meio do qual se aprende para ensinar na sala de aula}

Em 1995 ingressamos no programa de Pós-Graduação em Educação da Faculdade de Educação da Universidade de São Paulo, na área de concentração didática, com um pré-projeto cujo objetivo era desenvolver uma pesquisa que pudesse organizar uma base empírica que fosse capaz de subsidiar uma interpretação sobre o modo como se aprende para ensinar na sala de aula. Entramos em contato com a obra de Pierre Bourdieu, especialmente tendo em vista a estrutura dos conceitos de campo e habitus para se pensar questões sobre a prática docente e a constituição do campo educacional. Entre os autores que já haviam utilizado esses conceitos para explicar questões que pertencem ao âmbito da educação estavam Perrenoud (1993), Catani (1994) e Bueno (1996). A fertilidade dessas noções para o nosso objetivo residia no fato de que Bourdieu formulou uma teoria da ação prática, e o que buscávamos era saber como a prática de ensinar na sala de aula era aprendida. Para isso era inevitável produzir explicações sobre a constituição da mesma. Bourdieu mostrou que a efetivação de práticas exercidas social e coletivamente configuram um habitus, ou seja, práticas deixam de ser meros saberes práticos e configuram um comportamento que denominou habitus. Segundo ele, a racionalidade desse fenômeno opera do seguinte modo:

\footnotetext{
[...] é o sistema de disposições duráveis, estruturas estruturadas predispostas a funcionarem como estruturas estruturantes, isto é, como princípio que gera e estrutura as práticas e as representações que podem ser objetivamente "regulamentadas" e "reguladas" sem que por isso sejam os produtos de obediência de regras, objetivamente adaptadas a um fim, sem que se tenha necessidade da projeção consciente deste fim ou do domínio das operações para atingilo, mas sendo, ao mesmo tempo, coletivamente orquestradas sem serem o produto da ação organizadora de um maestro. (Bourdieu, 1972, in Ortiz, 1983, p. 15)
}

Especialmente por isso é que o conceito de habitus chamou a atenção, contribuindo mais uma vez para que a investigação fosse mantida, tendo em vista o dado de que os 700 alunos que se havia pesquisado anteriormente também diziam que era na prática que se aprendia a dar aula, e indiretamente atribuíam à didática a mesma natureza da prática. Para manter o raciocínio, é preciso ter sempre em mente que Bourdieu (1996a) formulou a noção de habitus em consonância com sua idéia de representação e sobre a força da representação na auto-organização objetivosubjetiva dos agentes no âmbito da ação prática. Isso está sendo observado porque as representações "representam" a compreensão dos sujeitos a partir da observação real, mesmo que seja imprescindível levar-se em conta que a construção das representações é operacionalizada dinamicamente com as informações cognitivas já estabelecidas. Faz-se necessário aceitar que a exterioridade das mesmas passa por refinamentos de significação e sua configuração estética pode estar mostrando algo que não pode ser percebido sem que a atenção esteja disciplinada e 
intencionalmente voltada para a estruturação do ato ou comportamento - nesse caso, o ensino na sala de aula. Reitera-se: deve-se sempre levar em consideração que as representações - conforme dizem diferentes lógicas conceituais que delas se ocuparam ou se ocupam Bourdieu (1992), Ginzburg (2001), dentre muitos outros - evidenciam uma base epistemológica por meio de ações, atitudes, raciocínios conjuntamente dispostos.

A latente possibilidade: será que quem não exerce o ensino na sala de aula diz que se aprende a dar aula na prática a partir das representações que construiu sobre o fazer docente durante a história de escolarização, pela exposição à prática de ensinar e pela observação da mesma? E professorandos que dizem que é na prática que se aprende a dar aula? Por exemplo, Mizukami (1983) mostrou que alunos de licenciatura, no ensino superior, que se preparavam para ser professores e professoras, afirmavam que aprendiam mais com a prática docente de seus mestres do que com as teorias sobre a prática docente que eles lhes ensinavam. E por fim: será que aqueles alunos pesquisados, e todos que afirmam (porque pensam e, portanto, têm estruturado objetiva e subjetivamente) que se aprende a dar aula na prática, tinham e têm razão? A frase "é na prática que se aprende a ser professor ou professora" é um discurso que no Brasil ninguém pode negar nunca ter ouvido de profissionais do ensino, de alunos e de pessoas que nunca exerceram o a profissão docente. Isso provoca muitas vezes desespero e desesperança na academia, tendo em vista o significado que uma afirmação como essa tem quando se está referindo à relação entre teoria e prática no âmbito da docência ou ao lugar de cada uma no referido fazer. ${ }^{7}$ Talvez isso ocorra porque o fazer docente, aos olhos do observador, é um fazer do campo

${ }^{7}$ Como já mencionado na introdução, atualmente as pesquisas estão apontando para o lugar no qual se aprende cada um desses domínios, sem que a relação entre a teoria e a prática seja confundida com as características específicas de uma e outra, tendo em conta o aprendizado das mesmas durante a formação do- prático da vida. O que também remete à noção de habitus como teoria explicativa do ato de ensinar realizado nas instituições escolares, obrigando a pensar o lugar do aprendizado da teoria e da prática na referida formação.

Thompson (1981) legitima explicitamente a racionalidade da noção de habitus em Bourdieu. Essa observação é feita a serviço das estruturas lógicas da noção de experiência, que Thompson formulou a partir da observação da prática da classe operária inglesa no processo de sua auto-organização. Para esse autor, o erro de Althusser, a quem dirige as críticas formuladas no texto em questão, consistia no fato de ele ter descrito a vida cotidiana baseada apenas nas leis econômicas gerais (segundo Thompson, tão brilhantemente descritas por Marx), sem observar a prática dos homens reais, obviamente no que dizia respeito aos modos de pensar e agir da classe operária inglesa. Essa observação levou Thompson (1981, p. 15) a afirmar que a experiência é fruto "de muitos acontecimentos inter-relacionados ou de muitas repetições do mesmo tipo de acontecimento"; por isso, parafraseando-o, a teoria marxista circunscrita nos gabinetes não pode alcançar a trama real que ocorre somente na prática dos homens, na qual ocorrem ações que não foram descritas pelas teorias porque são frutos da própria experiência.

Nesse sentido, pode-se considerar que a experiência adquirida pelos educadores sobre o ensino na sala de aula também é uma repetição de acontecimentos inter-relacionados, ou a repetição de determinadas e mesmas ações com determinado fins, que são frutos dos condicionantes práticos oriundos da natureza prática do ato de ensinar. A semelhança entre a lógica da noção de experiência e a noção de habitus é visível. O

cente. Levanta-se a hipótese de que a polêmica de caráter valorativo que se trava em torno de saberes teóricos e práticos ocorre devido também à falta de qualificação adequada das questões: investigar sobre a relação entre a teoria e a prática na formação e atuação docentes é muito diferente de investigar em que instância aprende-se a teoria e a prática para exercer a docência. 
que seguramente se pode dizer é que uma não existe sem a outra, já que o habitus é a substância da experiência, e vice-versa. Bourdieu e Thompson usaram a mesma lógica para formular instrumentos explicativos de denominações diferentes, mas logicamente semelhantes e intercomplementares sobre a ação prática dos homens. E é exatamente por isso que se acredita que habitus e experiência sejam duas noções fundamentais aos estudos sobre o lugar da teoria e da prática na formação e atuação docentes, tendo em conta a estruturação do objeto de estudo das investigações sobre o ato de ensinar na sala de aula.

A observação em sala de aula, um dos esteios dessa formulação, foi realizada em 1991 e 1992 em uma escola de Araraquara, escolhida em razão de um procedimento metodológico considerado imprescindível à continuidade dos estudos que realizávamos: 0 corpo docente daquela unidade permanecia o mesmo que tinha formado parte dos alunos entre 1987 e 1989, sujeitos dos dois primeiros estudos que também compõem essa síntese. Observaram-se aulas ministradas na disciplina didática e nas disciplinas de conteúdo e metodologia da língua portuguesa, da matemática e de estudos sociais. Como se pode notar, porque muito próximas da função da didática. Pode-se mesmo dizer que constituem uma didática especial.

\section{O que os dados coletados indicaram sobre o modo por meio do qual se aprende para ensinar na sala de aula}

Os dados coletados foram analisados com a contribuição da noção de habitus em Bourdieu e da categoria experiência em Thompson. A sistematização a que chegamos ${ }^{8}$ possibilitou afirmar que se aprende para ensinar na prática desse exercício. E ainda: é nesse e com esse exercício que se desenvolve o habitus professoral. Portanto, pode-se afirmar que o desen-

8 Essa pesquisa constituiu nossa tese de doutorado, já mencionada. Nnela está descrito detalhadamente o processo de coleta de dados, bem como o processo de análise dos mesmos. volvimento desse habitus se dá independentemente da formação didática específica e relaciona-se precariamente com a metodologia dos modelos de ensino disponíveis na literatura, que são ensinados na sala de aula dos cursos que preparam professores. ${ }^{9}$ Denominou-se habitus professoral o conjunto de ações que visivelmente eram exercidas pelo professor e pelas professoras (respectivamente, um professor e três professoras) observados, que recebiam respostas imediatas, objetivas e espontâneas de seus alunos, que estabeleciam relação direta com os gestos de ensino decididamente intencionais praticados por esses profissionais. A propósito, durante a observação (25 aulas de cinqüenta minutos cada uma) percebemos que os quatro professores que ministravam as disciplinas anteriormente mencionadas, quando diziam que iam explicar a matéria, comportavam-se do mesmo modo: levantavam-se, abriam o livro, impostavam a voz e liam o conteúdo. Esse comportamento era reproduzido independentemente do componente curricular, do período e do horário dentro do período. Os alunos, por sua vez, quando o professor dizia que ia explicar o conteúdo, colocavam o corpo em posição mais ereta, olhavam para ele com atenção e ficavam em silêncio. Gestos próprios do processo ensino-aprendizagem que são repetidos harmonicamente sem que tenha de ser dito pelos agentes; um conjunto de práticas repetidas coletivamente.

Esses comportamentos são explicados com as noções de experiência e habitus, que mostram que a vida prática é produzida por critérios e elementos que fazem parte das ações práticas que se repetem todos os dias em um determinado fazer, e que nelas há gestos corporais, apreciações, estilos que compõem aquela atividade, e não outra. Ademais, os sujeitos não se perguntam como devem se comportar em situações práticas repetitivas e coletivas; e, ainda, os sujeitos comportam-se harmonicamente, mesmo que tais ações

\footnotetext{
${ }^{9}$ Lembramos que os professorandos que fizeram parte do
} trabalho de Mizukami, mencionado anteriormente, já apontavam para isso. 
não estejam sendo exercidas num mesmo ambiente e numa mesma hora. Isso pode ser encontrado na citação que foi registrada anteriormente sobre a definição de habitus em Bourdieu (in Ortiz, 1983, p. 15). Pode-se dizer, então, que os estudos sobre a prática docente - cuja metodologia é a reflexão da prática docente exercida pelo agente que a efetiva - devem estar em um bom caminho. Sobretudo porque o habitus é uma estrutura estruturada estruturante. $\mathrm{Ou}$ seja: um habitus pode ser reestruturado com outras práticas, configurando um outro habitus.

Outra informação que corrobora o habitus como noção explicativa da ação prática de ensinar na sala de aula diz respeito ao fato de que quando o professor e as professoras liam o conteúdo que estava registrado no livro sem explicá-lo, os corpos dos alunos iam se arrefecendo e eram deixados cair nas carteiras e eram apoiados na parede, quando se tratava das fileiras de carteiras nela encostadas. Bourdieu denomina essa manifestação hexis corporal: um gesto harmonicamente repetido muitas vezes porque está estruturado objetiva e subjetivamente. Ou seja, tanto mestre quanto aprendiz manifestam gestos que materializam intenções específicas, e isso foi aprendido na prática de ser professor e na prática de ser aluno.

Observações como essas encorajaram-nos a dizer que há um habitus professoral que ainda é esperado pelo aluno - o de explicar a matéria -, e há outro que já está sendo estruturado pelo professor - o de ler sem explicar, como se o fizesse apenas com a leitura do texto. ${ }^{10}$ Essa última informação alargou a formulação desse entendimento, que ora se apresenta porque possibilitou entrever o lugar da teoria e o lugar da prática na formação e na atuação docentes. Isso foi peremptório para a afirmação do habitus professoral. Essa nova fresta abriu-se quando observamos que os professores manifestavam um tipo de habitus de ensinar que não era esperado pelos alunos. Mais do que isso: o habitus de ensino daqueles professores não era reconhecido pelo grupo de alunos observado

${ }^{10}$ Esse dado foi detalhadamente apresentado em Silva (2002). (por volta de 200 agentes), que estudavam nas disciplinas curriculares que diziam respeito aos modos de ensinar na sala de aula, ministradas pelos respectivos docentes. Iluminamos com a noção de habitus o descompasso gestual entre professor e alunos, e formulamos a seguinte idéia: aqueles alunos não respondiam adequadamente ao habitus professoral manifestado por seus professores porque não praticavam o ensino durante a formação; praticavam, sim, a aprendizagem. Portanto, se praticavam algum habitus era o de estudante, e não o de professor. No que ainda diz respeito ao descompasso gestual, podemos dizer que se originava do fato de que aqueles professores nunca haviam ensinado para aqueles alunos; que a explicação do texto era efetivada pela leitura, como mostrava o habitus que exibiam. ${ }^{11}$

Para reafirmar essa formulação, são muito úteis os trabalhos realizados com professores e professoras iniciantes. Por exemplo, a tese de Guarnieri (1996), intitulada Tornando-se professor: o início na carreira docente e a consolidação da profissão, mostra que é na prática que se aprende a ensinar na sala de aula que, reiteramos, se traduz no habitus professoral. Guarnieri informa que:

A partir de revisão de 91 estudos realizados em diferentes países, sendo que a maioria recorreu a questionários e poucos utilizaram entrevistas e observações, Veenman (1988) identifica os problemas mais sérios que os professores iniciantes (que ainda não completaram três anos de ensino) encontram ao se iniciarem na profissão. A disciplina em sala de aula é o problema mais sério percebido pelos professores iniciantes, os quais não conseguem explicitar regras e procedimentos para a classe. A motivação dos alunos aparece como outro problema, seguido da dificuldade do professor novo em lidar com as diferenças individuais entre os alunos. Os professores iniciantes apresentam dificuldades para avaliar o trabalho dos alunos; para relacio-

11 Outro resultado que aponta na direção dessa racionalidade, à luz da noção de habitus em Bourdieu, pode ser também encontrado na tese de Carneiro da Silva (1997). 
narem-se com os pais, com seus alunos e com a comunidade; são inexperientes em relação ao emprego dos meios audiovisuais; preocupam-se com a própria competência e seu preparo para a docência é insuficiente. Além dessas dificuldades, os professores iniciantes consideram que o ensino é um trabalho físico e mentalmente esgotador.

(Guarnieri, 1996, p.13-14, grifos meus)

Com base nessa citação, podemos, dentro de certo limite, afirmar que discentes não aprendem práticas específicas de mestres quando são estudantes. O primeiro problema mencionado na citação diz respeito à disciplina em sala de aula. Esse dado impõe dirigir o olhar para a situação real que ocorre nas salas de aula de qualquer nível de ensino e, sobretudo, quando se trata da formação de professores e professoras: os estudantes não organizam a disciplina de seus colegas nas classes em que estudam, isso é tarefa de seus mestres. Nos cursos de formação de docentes os alunos lêem e discutem sobre o tema "disciplina na sala de aula", mas não praticam a ação de manter a classe disciplinada como se fossem professores. Mesmo que se leve em consideração que estudantes apreendem "tipos de comportamentos" com seus professores e suas professoras (e pode-se dizer ao longo de qualquer tipo de formação), eles não praticam tais comportamentos quando são alunos. $\mathrm{O}$ aprendizado que advém da observação é intelectual, e não prático. Embora possa parecer que há uma contradição entre as afirmações: (a) discentes não aprendem a ser mestres quando são estudantes e (b) o aprendizado que advém da observação é intelectual, e não prático, nos limites estruturais da idéia básica dessa formulação a contradição não existe. Não existe porque, no caso da constituição do habitus professoral, a ação prática é, inexoravelmente, realizada com recursos teóricos que foram apreendidos abstratamente, ou seja, fora da aplicação. O que na estrutura lógica do habitus está no âmbito da subjetividade das ações, e na noção de experiência, na substância que a configura. Pode-se dizer, então, que o aprendizado teórico vai ser manifestado na prática do exercício que o convoca.
Outrossim, sempre a partir dos dados mostrados por meio da citação, estudantes não têm a responsabilidade de motivar outros para algum tipo de aprendizagem. Tampouco exercem alguma atividade que vise ao desempenho acadêmico dos colegas. Quem tem essa tarefa é o professor ou a professora. Alunos não precisam necessariamente avaliar trabalhos de colegas na sala de aula, exceto quando isso faça parte da metodologia empregada por determinado profissional numa disciplina curricular. Nesse sentido, alunos são avaliados e, de modo geral, não avaliam. As atividades que os alunos realizam na sala de aula, nos cursos dessa formação, são atividades aprendidas, na maioria das vezes, teoricamente, com vista a serem aplicadas quando da futura docência. Esses alunos não as apreendem como docentes, e sim como discentes que são.

Portanto, as dificuldades que são apresentadas por professores e professoras iniciantes são perfeitamente compreensíveis, já que durante a formação foram submetidos àquelas atividades e não exerceram as mesmas como devem ser quando profissionais da sala de aula nas escolas. Ou seja, durante a formação os discentes estruturam o habitus estudantil, e não o habitus professoral, pois o último será desenvolvido somente no e com o exercício da docência. E é exatamente por isso que se afirma que o ato de ensinar na sala de aula denomina-se habitus, e não prática docente, sobretudo quando o que está em jogo é a constituição do objeto das investigações sobre o ensino na sala de aula. No que diz respeito à formação de professores, a partir do raciocínio desenvolvido pode-se dizer que a teoria se aprende quando se está cursando a formação, mas a prática aprende-se quando se está exercendo a profissão, e somente com o exercício prático é que é desenvolvido e incorporado um tipo de habitus. Por isso afirmamos, na introdução, que esse estudo vai ao encontro da nova epistemologia da prática que vem sendo discutida por vários educadores. Para Tardif (2002, p. 287-278), essa epistemologia

\footnotetext{
[...] é baseada no princípio segundo o qual a prática profis-
} sional constitui um lugar original de formação e de produ- 
ção de saberes pelos práticos, pois ela é portadora de condições e de condicionantes específicos que não se encontram noutra parte nem podem ser reproduzidos "artificialmente", por exemplo, num contexto de formação teórica na universidade ou num laboratório de pesquisa.

\section{O fechamento do raciocínio}

Com base na reflexão apresentada, podemos dizer que o habitus professoral faz parte do conjunto de elementos que estruturam a epistemologia da prática. Trata-se, sobretudo, da estética desse ato, isto é, dos modos de ser e agir de professores e professoras. E essa estética é produzida por meio das influências inexoráveis dos condicionantes advindos da cultura estruturada e estruturante da escola, que subsiste na instituição na qual o sujeito desenvolve sua carreira docente. Outrossim, a produção desse habitus depende da qualidade teórica e cultural da formação dos professores, mas não é desenvolvido durante a formação, e sim durante o exercício profissional. Nesse sentido, a contribuição que ora oferecemos diz respeito aos tipos de saberes que compõem a base docente, tendo em vista suas demandas para a formação adequada dos profissionais que são formados em todos os níveis de ensino e para atuar em todos eles.

Em decorrência, considerou-se o habitus professoral o objeto de estudo do ensino do ato de ensinar na sala de aula, ou seja, para se entender o ensino na sala de aula é preciso investigar as estruturas estruturadas e estruturantes desse habitus manifestado pelos professores. Não obstante, não se pode desprezar o fato de que a estética do habitus professoral apresenta características específicas em cada nível de ensino e, ainda, entre grupos de professores no âmbito desses níveis. Ou seja, a natureza e a característica dos componentes curriculares que são ensinados na escola também definem a estética do habitus. E essas características, provocadas pela lógica interna da teoria que se ensina, são bastante visíveis quando olhamos para os modos de ser (pensar e agir) dos grupos de professores que ministram componentes curriculares distintos. Por exemplo, a estética do habitus professoral dos professores de biologia difere, claro que nas nuanças das ações, da estética do habitus professoral dos professores de língua portuguesa, e assim por diante. Sobre isso, Bourdieu explica com a relação de homologia: diversidade na homogeneidade (Bonnewitz, 2003, p. 80). Contudo, a estruturação do habitus professoral é comum a todos os profissionais do ensino na sala de aula. Caso o raciocínio construído seja verdadeiro, os 700 professorandos que diziam que se aprende na prática para ensinar na sala de aula estão corretos, como estão também todos os que dizem a mesma coisa. $\mathrm{O}$ fato de os referidos sujeitos terem colocado a didática na mesma posição funcional da prática de ensinar deveu-se, acredita-se, à natureza da didática, pois, a nosso juízo, o corpo teórico da didática somente pode existir objetivamente quando se operacionaliza um tipo de transposição didática do mesmo, ou seja, quando a teoria é transformada em prática. Caso seja assim mesmo, acabamos de explicar a contradição da qual partimos: aprende-se a ensinar durante o exercício da profissão, mas a didática, como disciplina, também ensina a ensinar durante a formação.

Não obstante, esse é apenas o início de uma conversa que aponta na direção de um longo caminho investigativo a ser percorrido, tão longo quanto o já cumprido até aqui. Que essa polêmica seja, para nosso leitor, leve e suficientemente provocativa.

MARILDA DA SILVA, pós-doutora pela Universidade de Lisboa, é professora na Faculdade de Ciências e Letras da Universidade do Estado de São Paulo (UNESP - campus de Araraquara). Publicou: Explicação do conteúdo: elemento estruturante da aprendizagem eficaz (Cadernos de Pesquisa, São Paulo, nº 115, março de 2002, p. 195-205); Como se ensina e como se aprende a ser professor: a evidência do habitus professoral e da natureza prática da didática (Bauru: EDUSC, 2003); Metáforas e entrelinhas da profissão docente (São Paulo: Pioneira Thomson Learning, 2004). Projeto de pesquisa em desenvolvimento: O habitus professoral: o objeto dos estudos do ato de ensinar na sala de aula. E-mail: marilda@fclar.unesp.br 


\section{Referências bibliográficas}

ANDRÉ, M. E. D., (1988). Em busca de uma didática fundamental. In: CANDAU, V. M. (coord.). Rumo a uma nova didática. Petrópolis: Vozes, p. 147-156.

, (1992). A evolução do ensino de didática. Revista da Faculdade de Educação, São Paulo, v. 18, nº 2, p. 241-246.

ANDRÉ, M. E. D. et al., (1984). Análise dos programas de didática do Estado do Rio de Janeiro. Tecnologia Educacional, Rio de Janeiro, $n^{\circ}$ 59, jul./dez, p. 20-23.

ANDRÉ, M. E. D. A., MEDIANO, Z. D., (1988). O cotidiano da escola: elementos para a construção de uma didática fundamental. In: CANDAU, V. M. (coord.). Rumo a uma nova didática. Petrópolis: Vozes, p. 157-168.

BONNEWITZ, P., (2003) Primeiras lições sobre a sociologia de P. Bourdieu. Petrópolis: Vozes. Tradução de Lucy Magalhães. BOURDIEU, P., (1983a). Algumas propriedades do campo. In: BOURDIEU, P. Questões de sociologia. Rio de Janeiro: Marco Zero, p. 89-94. Tradução de Jeni Vaitsman.

, (1982b). O campo científico. In: ORTIZ, R. (org.). Pierre Bourdieu: sociologia. São Paulo: Ática, p. 122-155. Tradução de Paula Montero e Alicia Auzmendi.

, (1983c). Esboço de uma teoria da prática. In: ORTIZ, R. (org.). Pierre Bourdieu: sociologia. São Paulo: Ática, p. 46-81. Tradução de Paula Montero e Alicia Auzmendi.

, (1983d). Gostos de classe e estilos de vida. In: ORTIZ,

R. (org.). Pierre Bourdieu: sociologia. São Paulo: Ática, p. 82121. Tradução de Paula Montero e Alicia Auzmendi. , (1989). A gênese dos conceitos de habitus e de campo. In: BOURDIEU, P. O poder simbólico. Rio de Janeiro: Bertrand Brasil, p. 59-73. Tradução de Fernando Tomaz.

, (1992). Campo do poder, campo intelectual e habitus de classe. In: BOURDIEU, P. Economia das trocas simbólicas. Rio de Janeiro: Perspectiva, p. 201-202. Tradução de Sergio Miceli, Silvia de Almeida Prado, Sonia Miceli e Wilson Campos Vieira.

, (1996a). A força da representação. In: BOURDIEU,

P. A economia das trocas linguísticas: o que falar quer dizer. São Paulo: Ed. Universidade de São Paulo, p. 107-116. Tradução de Sergio Miceli, Mary Amazonas Leite de Barros, Afrânio Catani, Paula Montero e José Carlos Durand.

(1996b). Razões práticas: sobre a teoria da ação.

Campinas: Papirus. Tradução de Mariza Corrêa.
BUENO, B. O., (1996). Autobiografia e formação de professores: um estudo sobre representações de alunas de um curso de magistério. Tese de livre-docência. Faculdade de Educação da Universidade de São Paulo.

CANDAU, V. M., (1988a). A didática e a relação forma/conteúdo. In: CANDAU, V. M. (coord.). Rumo a uma nova didática. Petrópolis: Vozes, p. 26-32.

, (1988b). A formação de educadores: uma perspectiva multidimensional. In: CANDAU, V. M. (coord.). Rumo a uma nova didática. Petrópolis: Vozes, p. 43-48.

, (1988c). A relação teoria-prática na formação do educador. In: CANDAU, V. M, (coord.). Rumo a uma nova didática. Petrópolis: Vozes, p. 49-63.

, (1988d). A revisão da didática. In: CANDAU, V. M. (coord.). Rumo a uma nova didática. Petrópolis: Vozes, p. 13-18. , (1988e). Tem sentido hoje falar de uma didática geral? In: CANDAU, V. M., (coord.). Rumo a uma nova didática. Petrópolis: Vozes, p. 33-39.

, (1988f). A didática em questão. $7^{\mathrm{a}}$ ed. Petrópolis: Vozes.

CANDAU, V. M., LELLIS, I. A., (1983). A relação teoria-prática na formação do educador. Tecnologia Educacional, Rio de Janeiro, v. $12, \mathrm{n}^{\mathrm{o}} 55$.

CARNEIRO DA SILVA, W., (1997). La formation des maîtres à l'Université: analyse sociologique des expériences dans trois facultés de la ville de Rio de Janeiro (Brésil). Tese de doutorado. Université René Descartes.

CARVALHO, C. P. de, (1988). Ensino noturno: realidade e ilusão. $2^{a}$ ed. São Paulo: Cortez e Autores Associados.

CASTRO, A. D. de, (1984). A didática na Revista Brasileira de Estudos Pedagógicos. Revista Brasileira de Estudos Pedagógicos, Brasília, v. 64, nº 150, maio/ago., p. 291-300.

, (1992). A memória do ensino de didática e prática de ensino no Brasil. Revista da Faculdade de Educação, São Paulo, v. 18, nº 2, jul./dez., p. 233-239.

CATANI, D. B., (1994). Ensaios sobre a produção e circulação dos saberes pedagógicos Tese de livre-docência. Faculdade de Educação da Universidade de São Paulo.

, (1985). A didática que se ensina e a didática que se usa: análise dos pressupostos da discussão. In: SEMINÁRIO A DIDÁTICA EM QUESTÃO, 3., São Paulo. Resumos... São Paulo: EDUSP, p. 73.

COMÉNIO, J. A., (1957). Didática magna: tratado da arte universal de ensinar tudo a todos. $5^{\mathrm{a}}$ ed. Lisboa: Fundação Calouste Gulbenkian. 
CUNHA, M. V. da, (1994). John Dewey: uma filosofia para educadores em sala de aula. Petrópolis: Vozes.

DAMIS, O. T., (1988). Didática: suas relações, seus pressupostos. In: VEIGA, I. P. (coord.). Repensando a didática. Campinas: Papirus, p. 13-24.

DEWEY, J., (1976). Experiência e educação. $2^{\mathrm{a}}$ ed. São Paulo: Editora Nacional .

ENCONTRO NACIONAL DE DIDÁTICA E PRÁTICA DE ENSINO, 4., (1987). Resumos... Recife: Universidade Católica de Pernambuco.

GASPARIN, J. L., (1992). Comênio ou da arte universal de ensinar tudo a todos totalmente Tese de doutorado em História e Filosofia da Educação. Pontifícia Universidade Católica de São Paulo.

GAUTHIER, C. et al., (1998). Por uma teoria da pedagogia: pesquisas contemporâneas sobre o saber docente. Ijuí: UNIJUÍ.

GINZBURG, C., (2001). Olhos de madeira: nove reflexões sobre a distância. São Paulo: Companhia das Letras. Tradução de Eduardo Brandão.

GUARNIERI, M. R., (1996). Tornando-se professor: o início na carreira docente e a consolidação da profissão. Tese de doutorado em Metodologia do Ensino. Universidade Federal de São Carlos.

LIBÂNEO, J. C., (1983). Tendências pedagógicas na prática escolar. Revista da ANDE, São Paulo, v. 3, nº 6, p. 11-19.

MARIN, A. J., (1984). Os estudos didáticos no Brasil: algumas idéias. Revista Didática, São Paulo, v. 20, p. 61-67.

MARTINS, P. L. O., (1989). Didática teórica - didática prática: para além do confronto. São Paulo: Loyola.

MIZUKAMI, M. G. N., (1983). Ensino: o que fundamenta a ação docente? Tese de doutorado em Metodologia do Ensino. Pontifícia Universidade Católica do Rio de Janeiro.

OLIVEIRA, M. R. N. S., (1988). A didática e seu objeto de estudo. Educação - Revista da Faculdade de Educação de Belo Horizonte, Belo Horizonte, p. 36-41.

ORTIZ, R., (1983). A procura de uma sociologia da prática. In: ORTIZ,

R. (org.). Pierre Bourdieu: Sociologia. São Paulo: Ática, p. 7-29. PERRENOUD, P., (1993). Práticas pedagógicas: profissão docente e formação, perspectivas sociológicas. Lisboa: Dom Quixote. SEMINÁRIO A DIDÁTICA EM QUESTÃO, 1., (1982). Atas...

Rio de Janeiro: Pontifícia Universidade Católica.

SEMINÁRIO A DIDÁTICA EM QUESTÃO, 2., (1983). Anais... Rio de Janeiro: Pontifícia Universidade Católica.
SEMINÁRIO A DIDÁTICA EM QUESTÃO, 3., (1985). Atas...2 v. São Paulo: Universidade de São Paulo.

SEMINÁRIO A DIDÁTICA EM QUESTÃO, 3., (1985). Resumos... São Paulo: Universidade de São Paulo.

SILVA, A. M. M., (1985). Estudo sobre o ensino de didática no $2^{\circ}$ grau e sua aplicabilidade na prática pedagógica de $1^{\mathrm{a}}$ à $4^{\mathrm{a}}$ série do $1^{\circ}$ grau. In: SEMINÁRIO A DIDÁTICA EM QUESTÃO, 3. Resumos... São Paulo: EDUSP, p. 33.

, (1983). Análise dos programas de didática dos cursos de pedagogia e licenciaturas diversas do Estado de Pernambuco. In: SEMINÁRIO A DIDÁTICA EM QUESTÃO, 2. Atas... Rio de Janeiro: PUC, p. $100-110$.

SILVA, M., (2002). Explicação do conteúdo: elemento estruturante da aprendizagem eficaz. Cadernos de Pesquisa, São Paulo, n. 115 , p. 195-205.

, (1993/1994). O alunado de uma escola particular noturna de formação de professores. Revista Didática, São Paulo, no 29, p. 45-53.

, (1994). O movimento a didática em questão: alguns de seus embaraços. Dissertação de mestrado em História e Filosofia da Educação. Pontifícia Universidade Católica de São Paulo.

,(1995). Controvérsias em didática. São Paulo: Papirus. , (1999). As experiências vividas na formação e a constituição do habitus professoral: implicações para o estudo da didática. Tese de doutorado em Didática. Faculdade de Educação da Universidade de São Paulo.

, (2003). Como se ensina e como se aprende a ser professor: a evidência do habitus professoral e da natureza prática da didática. Bauru: EDUSC.

SILVA, M., MARIN, A. J., (1989). Didática e formação de professores de $2^{\circ}$ grau: o cotidiano na visão dos alunos. Revista Didática, São Paulo, v. 25, p. 63-78.

SOARES, M. B., (1985). Didática, uma disciplina em busca de sua identidade. Revista da ANDE - Revista da Associação Nacional de Educação, São Paulo, v. 5, nº 9, p. 39-42.

TARDIF, M., (2002). Saberes docentes e formação profissional. Petrópolis: Vozes.

THOMPSON, E. P., (1981). A miséria da teoria ou um planetário de erros. Rio de Janeiro: Zahar.

VEIGA, I. P. A., (1988). Didática: uma retrospectiva histórica. In: VEIGA, I. P. A. (coord.). Repensando a didática. Campinas: Papirus, p. 25-40. 


\title{
Resumos/Abstracts
}

\author{
Marilda da Silva \\ O habitus professoral: o objeto dos estudos sobre o ato de ensinar na sala de aula \\ Este artigo objetiva definir o conceito intitulado "habitus professoral", esforço que vem sendo feito desde o fim da década dos \\ anos de 1980, mas que somente no final dos anos de 1990 conseguiu alcançar uma estrutura teórica mais estável. "Habitus profes- \\ soral" é o caminho teórico-metodológico da construção de um recurso explicativo dos comportamentos de professores, sobretudo, \\ do re-endereçamento do objeto de estudo do ato de ensinar na sala de aula. Os lugares da teoria e da prática na formação e atuação \\ docentes foram simultaneamente analisados, servindo de ferramentas para a formulação do conceito em questão. As idéias de \\ Pierre Bourdieu e Edward Palmer Thompson (habitus e experiência) constituíram o núcleo do referencial teórico desta investiga- \\ ção.
}

Palavras-chave: habitus professoral; ensino em sala de aula

Professorial habitus: the object of studies about the act of teaching in the classroom

This article is an attempt to define the proposed concept of "professorial habitus", a process that has been un der way since the end of the 1980's. However, the attempt to produce a more stable theoretical structure for the concept took until the end of the 1990's. "Professorial habitus" is the theoretical-methodological way of building a resource capable of explaining teachers' behaviour and, above all, of re-addressing the object of study directed at the act of teaching in the classroom. The place of theory and practice in the formation and activity of teachers was investigated simultaneously and, at the same time, served as a tool for formulating the concept in question. The ideas of Pierre Bourdieu and Edward Palmer Thompson (habitus and experience) constituted the core of the theoretical framework of this investigation.

Key-words: professorial habitus; classroom teaching 